\title{
Assessment of the American Woodcock Singing-Ground Survey Zone Timing and Coverage
}

JOSEPH D. MOORE, ${ }^{1,2}$ Arkansas Cooperative Fish and Wildlife Research Unit, Department of Biological Science, University of Arkansas, Fayetteville, Arkansas, 72701, USA

THOMAS R. COOPER, Migratory Bird Program, U.S. Fish and Wildlife Service, 5600 American Blvd West, Suite 99o, Bloomington, Minnesota, 55437, USA

REBECCA RAU, Population and Habitat Assessment Branch, Division of Migratory Bird Management, U.S. Fish and Wildlife Service, 11510 American Holly Dr, Laurel, Maryland, 20708, USA

DAVID E. ANDERSEN, U.S. Geological Survey, Minnesota Cooperative Fish and Wildlife Research Unit, Department of Biological Science, University of Minnesota, St. Paul, Minnesota, 55108, USA

JEFFREY P. DUGUAY, Louisiana Department of Wildlife and Fisheries, Baton Rouge, Louisiana 70898

C. ALAN STEWART, Michigan Department of Natural Resources, Lansing, Michigan, 30444, USA

DAVID G. KREMENTZ, U.S. Geological Survey, Arkansas Cooperative Fish and Wildlife Research Unit, Department of Biological Science, University of Arkansas, Fayetteville, Arkansas, 72701, USA

\begin{abstract}
The American woodcock (Scolopax minor; hereafter, woodcock) Singing-Ground Survey (SGS) was developed to inform management decisions by monitoring changes in the relative abundance of woodcock. The timing of the designated survey windows was designed to count resident woodcock while minimizing counting of migrating woodcock. Since the implementation of the SGS in 1968, concerns over survey protocols that may bias data have been raised and investigated; however, the extent of survey coverage and the timing of the survey window zones have not been critically investigated. We used 3 years of data collected from male and female woodcock marked with satellite tags to assess the extent of survey coverage and the timing of the SGS survey windows relative to presence of woodcock. SGS coverage encompassed the majority of woodcock breeding-period sites (locations where marked woodcock returned to in spring) within the U.S. ( $n=17,92 \%)$ and approximately half of the breeding-period sites in Canada $(n=6,43 \%)$. Thirteen of the 37 monitored woodcock with known breeding-period site arrival dates $(35 \%)$ were migrating through a survey zone during an active survey window, all in the northernmost 4 of 5 SGS zones. Thirteen woodcock arrived at breeding-period sites after the start of surveys, and all but one of these was located in the northernmost 2 zones. The combination of migration through a SGS zone during the survey window and arrival at breeding-period sites after the beginning of the survey window in northern zones may result in the SGS weighing too heavily the contribution of routes in the southern portion of the primary breeding range, while weighing too lightly the routes in the northern portion of the primary breeding range. We suggest that additional information is necessary to evaluate whether current survey windows are sufficient, or whether they need to be changed.
\end{abstract}

Proceedings of the American Woodcock Symposium 11: 181-192

KEY WORDS: Population management, satellite transmitters, Scolopax minor, survey design

1 email: Joseph_Moore@fws.gov

2 current affiliation: U.S. Fish and Wildlife Service, Utah Ecological Services Field Office,

West Valley City, Utah

https://doi.org/10.24926/AWS.o124 
The American woodcock (Scolopax minor; hereafter, woodcock) Singing-Ground Survey (SGS) was developed to monitor changes in relative abundance of woodcock by exploiting the conspicuous courtship display of the male woodcock (Cooper and Kelley 2010). Several studies suggest that counts of singing males can provide a reliable index to woodcock populations and can be used to monitor annual changes in abundance (Mendall and Aldous 1943, Kozicky et al. 1954, Goudy 1960, Duke 1966, Whitcomb 1974, Tautin et al. 1983). The SGS is composed of approximately 1,500 routes covering the central and northern portions of the woodcock breeding range (Fig. 1).
Survey routes are located along lightly traveled secondary roads within randomly chosen 10-minute degree blocks for each state and province covered by the survey. Each route is $5.4 \mathrm{~km}$ long with 10 listening stops that are spaced at $0.6 \mathrm{~km}$ intervals. Observers survey the routes shortly after sunset and record the number of individual woodcock heard peenting (one vocalization of displaying male woodcock) over a period of 2 minutes at each stop.

Acceptable dates for conducting the survey align with latitudinal bands intended to coincide with peaks in courtship behavior of resident woodcock (Fig. 1). In most states, the peak of courtship activity (including resident

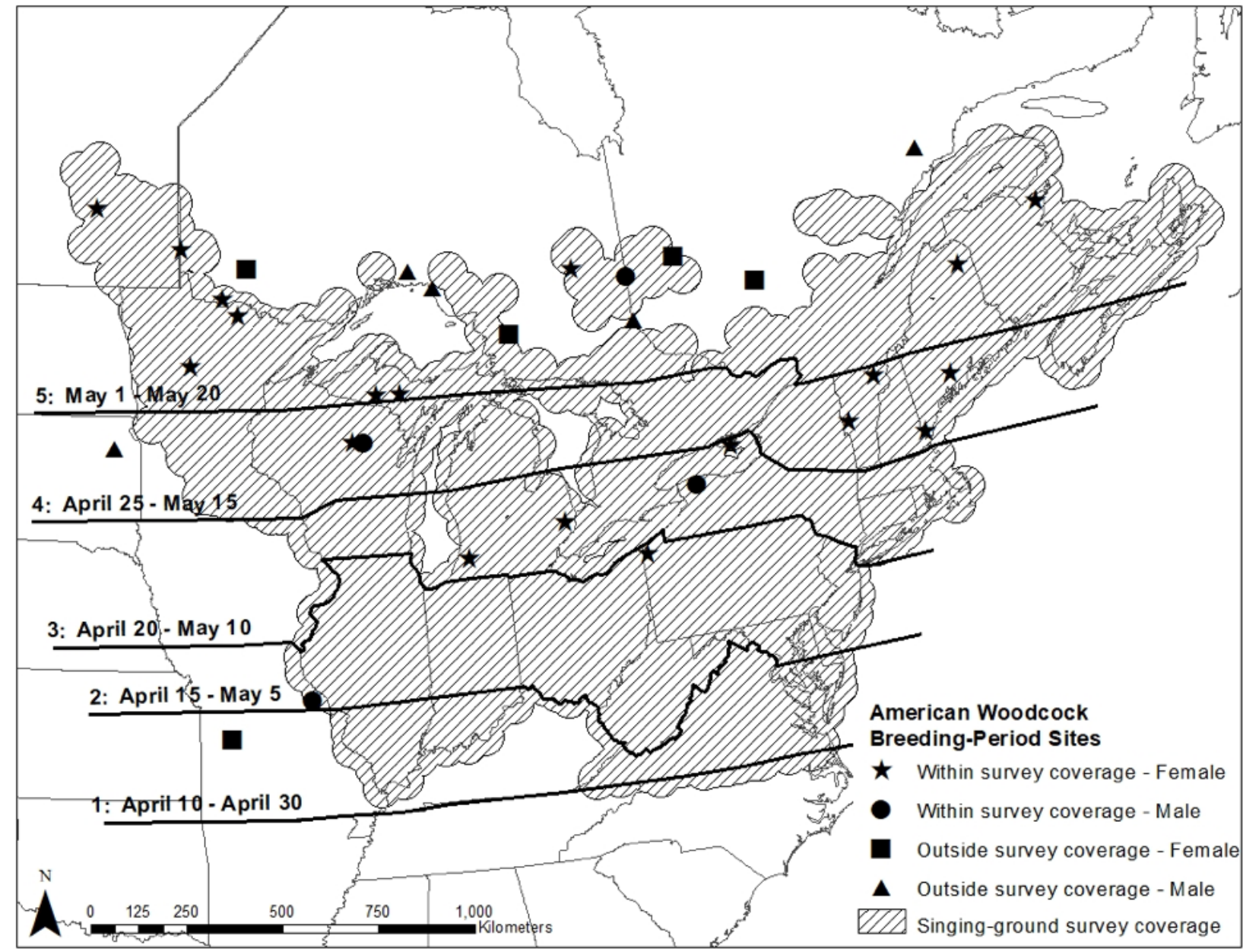

Figure 1: Spatial extent of the American woodcock Singing-Ground Survey (SGS) coverage, spatial extent and temporal windows of SGS zones, and breeding-period sites of 33 PTT-marked American woodcock. We estimated the extent of SGS survey coverage by buffering the center point of each 10-degree block containing an official SGS route by $50 \mathrm{~km}$ (except in Quebec, where the starting point of each SGS route was buffered). PTT-marked woodcock were captured during the winter period in Texas $(n=9)$ and Louisiana $(n=24)$. Twenty-three woodcock migrated to breeding-period sites within SGS coverage and 10 woodcock migrated to breeding period sites outside of SGS coverage. Breeding-period sites outside of SGS coverage are in Missouri $(n=1)$, Ontario $(n=5)$, Quebec $(n=3)$, and South Dakota $(n=1)$. 
woodcock and transient woodcock still migrating) may occur earlier in the spring and local reproduction may already be underway during survey windows. However, the timing of the designated survey windows (20 days in length) was designed to count woodcock that have settled in an area while minimizing counting migrating woodcock to the best extent possible (Goudy 1960, Duke 1966, Tautin et al. 1983). The 20-day survey window also allows for flexibility to complete routes given unpredictable weather conditions and observer scheduling conflicts. Survey protocols provide guidance for acceptable environmental conditions (e.g., wind, precipitation, and temperature) to avoid adverse weather conditions that may affect courtship behavior or the ability of observers to hear woodcock.

Data from the SGS are used to inform hierarchical models to estimate woodcock population indices and the most recent 2-year, 10-year, and long-term (1968 - present) trends for both the Eastern and Central Management Regions (Seamans and Rau, this volume). Data from the SGS have been used to inform management for a number of purposes, including 1) harvest management decisions (Woodcock Harvest Strategy Working Group 2010), 2) development of harvest strategies (Woodcock Harvest Strategy Working Group 2010), 3) development of spatially-explicit population and habitat goals based on historical and contemporary SGS data (Kelley et al. 2008), and 4) spatially-explicit models relating woodcock abundance and landscape-level variables (Thogmartin et al. 2007, Loman et al. 2017). The indices and trends derived from SGS data continue to be relied on for both management decisions and research.
Since the implementation of the SGS in 1968, concerns over survey protocols that may bias data have been raised and investigated. We grouped these concerns into five general sets of variables (Table 1). Two aspects of the SGS that have not been critically investigated are the extent of survey coverage and the timing of the survey windows within survey zones. The timing of the SGS by zone is of particular concern because detecting migrating woodcock and counting those individuals as resident breeders could have consequences for trend estimation. Double counting individual woodcock within and among SGS zones, states, provinces, or management units is a by-product of improper timing. If the timing of migration varies among years, double counting at the state, provincial, or management-unit scales may not be constant and short-term trends would be biased. Tautin et al. (1983:380) summarized the current SGS zone timing as follows:

\section{"Routes should be run during a three-week period beginning April 10 in southern portions of survey regions and ending May 20 in the most northern portions. Sexual recrudescence occurs early in woodcock; males occasionally begin exhibiting courtship behavior on wintering areas and continue through migration. The recommended dates focus the survey period after most migrants have passed through an area, thus minimizing the possibility of counting transient males."}

Previous investigation of survey windows in SGS zones was based on observations of unmarked displaying males

Table 1. Factors that may influence American woodcock singing-ground survey results as reported by various authors, 1955-2011.

\begin{tabular}{|c|c|c|}
\hline \multicolumn{2}{|l|}{ Factor Studied } & \multirow{2}{*}{$\begin{array}{l}\text { References } \\
\text { Mendall and Aldous (1943), Goudy (1960), } \\
\text { Tautin (1982) }\end{array}$} \\
\hline Scheduling & $\begin{array}{l}\text { Daily survey starting time and } \\
\text { ending time }\end{array}$ & \\
\hline Time-of-day effects & & Duke (1966) \\
\hline \multirow[t]{3}{*}{ Observer ability } & Observer effects & Goudy (1960), Duke (1966), Tautin (1982) \\
\hline & Survey participation pattern effects & Cooper and Kelley (2010) \\
\hline & Noise effects & Goudy (1960) \\
\hline \multirow[t]{4}{*}{ Environmental conditions } & Weather effects & Duke (1966) \\
\hline & Moon phase effects & Mendall (1955), Goudy (1960), Duke (1966) \\
\hline & Temperature effects & Goudy (1960), Dwyer et al. (1988 \\
\hline & Wind velocity effects & Blankenship (1954), Goudy (1960), Bergh (2011) \\
\hline \multirow[t]{3}{*}{ Other variables } & $\begin{array}{l}\text { Effects of changing habitat along } \\
\text { survey routes }\end{array}$ & $\begin{array}{l}\text { Dwyer et al. (1988), Morrison et al. (2010), Nelson } \\
\text { and Andersen (2013), Bergh (2011) }\end{array}$ \\
\hline & Woodcock density effects & Duke (1960), Bergh (2011) \\
\hline & Probability of detection along routes & Bergh (2011) \\
\hline
\end{tabular}


and may have included both migrating and breeding woodcock. Goudy (1960), working in southern Michigan, suggested that surveys run from 20 April - 10 May, whereas Duke (1966), working in southern Michigan, suggested that surveys run from 15 April - 15 May. Dwyer et al. (1988) compared statistically derived estimates of local woodcock populations on their study area (Maine) against SGS results for the 2 counties that overlapped their study area and concluded that the timing of the SGS or observer quality resulted in different temporal patterns of woodcock abundance. Whiting (2010) reexamined the survey window assessments of both Goudy (1960) and Duke (1966) and concluded that, in both of their studies, migrating woodcock were counted. Based on his reexamination of these results, Whiting (2010:155) concluded that "The magnitude of including migrating males in continental-wide population estimates has not been quantified and warrants further evaluation."

We used 3 years of data collected from male and female woodcock marked with satellite transmitters to assess the extent of SGS coverage and timing of the SGS survey windows. We assessed 1) whether transmitter-marked woodcock chose breeding-period sites (locations where marked woodcock returned in the spring) outside SGS coverage; 2) if migration was ongoing during survey windows, suggesting there may be the potential to double count woodcock; and 3 ) if individuals arrived at breeding-period sites after the start of the survey window, suggesting that there may be potential to undercount woodcock. Information on timing of SGS windows relative to presence of resident woodcock will enable decision makers to assess if changes to the SGS survey windows are necessary.

\section{Study Area}

Woodcock are resident during the breeding period throughout eastern North America and are managed on the basis of an Eastern and a Central Management Region, where management region boundaries are analogous to those of the Atlantic and Mississippi Flyways (Seamans and Rau, this volume, American woodcock population status). To represent woodcock across the breeding-period and wintering distribution within the Central Management Region, we captured woodcock across a large area in the northern and southern portion of the Central Management Region within the United States. We captured woodcock at sites during the breeding period in Minnesota, Michigan, and Wisconsin, during the wintering period in Louisiana and Texas, and 1 woodcock we presumed to be migrating during spring in northwestern Arkansas (Fig. 1). We chose specific study sites primarily to facilitate woodcock capture. In addition to study sites where we captured woodcock, our study area encompassed the locations to which transmitter-marked woodcock migrated, which included portions of the Eastern Management Region.

\section{Methods}

We trapped 75 woodcock between September 2013 and February 2016 using spotlights and hand-held nets at night both while on foot and from all-terrain vehicles (Rieffenberger and Kletzly 1967). We also trapped woodcock using mistnets during the crepuscular period (McAuley et al. 1993), and captured 1 woodcock with a hand-held net and a trained pointing dog during daylight. We captured woodcock close to the initiation of migration (either fall or spring) to reduce the risk of mortality or transmitter failure before migration began. Before spring migration, we captured woodcock between 5 January and 16 February; before fall migration, we captured woodcock between 18 September and 3 November. We determined age, sex, and mass of captured woodcock (Martin 1964), and banded all woodcock with an aluminum band issued by the U.S. Geological Survey. We attached satellite transmitters, also knowns as Platform Transmitter Terminals (PTT), using a modified thigh harness, where the PTT rested on the woodcock's lower back and was secured by loops over each leg (Rappole and Tipton 1991, Streby et al. 2015). We constructed PTT harnesses with 2 strands of o.7mm Stretch Magic elastic plastic cord (Pepperell Braiding Company, Pepperell, MA) threaded through Tygon tubing (Saint Gobain, Courbevoie, France; Hughes et al. 1994) crimped with metal rings. We performed this study under protocols approved by the Institutional Animal Care and Use Committee (IACUC) at the University of Arkansas, protocol \# 15011, and by the IACUC at the University of Minnesota, protocol \# 1408-31777A.

\section{SATELLITE TRANSMITTERS}

We equipped woodcock with 3 types of PTTs: a 9.5-g PTT, a 5-g PTT, and a 4.9-g GPS PTT. The 9.5-g and 5-g PTTs (Microwave Telemetry, Columbia, MD) were solar-powered and transmitted messages on a 10-hour-on and 48-hour-off duty cycle. The Argos Data Collection and Location System (Service Argos Inc., Landover, MD) estimated woodcock locations using the Doppler shift of transmissions originating from the PTTs (Argos 2016). Associated with each location was a location class that provided estimated error. Reported location errors were between 250 and 1,500 $\mathrm{m}$ or had no error estimation (Argos 2016). These PTTs had auxiliary sensors that provided information on temperature, voltage, and activity (i.e., whether the PTT changed orientation). We censored location data from PTTs when auxiliary sensors indicated that the tag was no longer moving and the temperature had dropped to ambient, or when we stopped receiving messages. The battery powered 4.9-g GPS PTTs (Lotek Wireless, Newmarket, Ontario, Canada) had only enough charge to collect 30 GPS locations along 1 migration path. Before deployment, we programmed the times and dates these 30 GPS locations would be collected. After collecting the GPS loca- 
tions, the PTT attempted to transmit all the location data to the Argos system on a 6-hour-on and 6-hour-off duty cycle. The Argos system used Doppler shift to collect additional locations while the GPS PTTs transmitted GPS locations. In spring 2016, we programmed GPS transmitters to record 1 location on 24 January, 1 location on 31 January, a location every 3 days from 7 February to 1 May, and a final location on 8 May. Transmitter mass did not exceed $5 \%$ of the individual's body mass, and we received an exception from the U.S. Geological Survey Bird Banding Laboratory to exceed the standard $3 \%$ body mass restriction for auxiliary markers. We deployed 9.5-g PTTs only on females with mass $>200 \mathrm{~g}$, whereas we deployed 5-g PTTs and 4.9-g GPS PTTs on males and females with mass $>150 \mathrm{~g}$.

\section{DATA ANALYSIS}

Seven of the tagged woodcock were monitored over multiple spring migrations. Preliminary analysis of these tracked woodcock indicated that most individuals exhibited fidelity to breeding-period sites and used similar spring migration routes among years (Moore 2016). Therefore, we used only the first recorded spring migration from an individual transmitter-marked woodcock to avoid pseudoreplication. We used the Movebank tracking data map (Kranstauber et al. 2011, Wikelski and Kays 2016) to identify clusters of location points and to classify points as spring migratory stopovers or breeding-period sites. We mitigated the influence of implausible Argos locations by using clusters of $\geq 2$ successive Argos locations to define stopover sites (Douglas et al. 2012). Implausible locations were less of a concern with GPS tags, because woodcock migrate nocturnally nighttime locations could reflect migration rather than stopover sites. We thus classified clusters of $\geq 2$ successive nocturnal GPS locations (taken every 3 days) as stopovers, whereas we classified single diurnal GPS locations as stopovers. We used location proximity, time between locations, and Argos location class to determine whether locations were clustered under the assumption that spatial and temporal autocorrelation confirm the validity of the location (Douglas et al. 2012). We chose reasonable criteria to define wintering, stopover, and breeding-period sites by defining the first wintering site as a site where a woodcock remained for $>25$ days and had no further movement $>50 \mathrm{~km}$ southward. We defined subsequent sites as wintering sites until the first northward movement $>25 \mathrm{~km}$ began. We classified sites between wintering-period and breeding-period sites as migratory stopovers. We determined the date of arrival at a breeding-period site using the date midway between the last known migratory location and the first location at a breeding-period site. We determined the coordinates of each stopover by taking the median center of all locations within the cluster (Arizaga et al. 2014). We did not consider arrival or departure dates when the gap between the last known location at a site and the first migratory location was $>10$ days (Martell et al. 2001, Arizaga et al. 2014, Olson et al. 2014). We defined the first breeding-period site as a site where a woodcock remained for $>25$ days and had no further northward movement $>50 \mathrm{~km}$. We chose these criteria to define breeding-period sites because they seemed reasonable and could be uniformly applied to our sample.

We determined the number of days spent at a stopover as the period between the first and last locations recorded at that site. Because transmitters typically had $48-72$ hours off duty cycles, and because there were additional gaps from transmitters missing "on" duty cycles (low battery power, the PTT not being able to charge and/or transmit because of heavy vegetation cover), the number of days at each stopover is a minimum number of days at a site. In addition, we were not able to document stopovers shorter than the duration between consecutive "on" cycles; therefore, our estimate of the number of stopover sites is also a minimum. The SGS was developed to monitor changes in relative abundance of woodcock by exploiting the conspicuous courtship display of the male woodcock (Cooper and Kelley 2010); however, our sample of arrival dates at breeding-period sites consisted primarily of female woodcock (female: $n=30$, male: $n=7$ ). To generalize our data on spring migration arrival dates of female woodcock to both male and female woodcock, we tested for the effect of sex on arrival date using a one-way ANOVA.

We estimated the extent of SGS survey coverage by buffering the center point of each 10-degree block containing an official SGS route by $50 \mathrm{~km}$ (except in Quebec, where we buffered the starting point of each SGS route, Fig. 1). After experimenting with several buffer sizes, we chose the $50-\mathrm{km}$ buffer because this distance produced a continuous surface between most adjacent survey points while limiting the amount of buffer extending into states that do not participate in the SGS. To determine if woodcock breeding-period sites were within SGS coverage we plotted breeding-period sites of transmitter-marked woodcock captured during the wintering-period in Texas and Louisiana over the polygon of SGS coverage and identified all sites north or west of coverage or within any coverage gaps. We used this sample of only woodcock captured during the wintering period to assess the spatial coverage of the SGS because preliminary analysis of these tracked woodcock indicated that most individuals exhibited fidelity to breeding-period sites among years (Moore 2016), and we used a sample of woodcock captured during either the breeding and wintering period to assess the temporal coverage. We compared the arrival dates of woodcock at breeding-period sites to the dates of the SGS survey windows to determine if any woodcock arrived in a survey zone after the close of the survey window, partially into the survey window, or were present in a zone when the survey windows were open and later moved to a breeding-period 
site in a different zone, state, or Management Region. To visualize the presence of transient migratory woodcock in reference to the start and close of the survey window in each zone, we plotted locations when woodcock were present at migratory stopovers against the latitude of locations of these migratory stopovers (Fig. 2). We then plotted a polygon enclosing the opening dates of each SGS window and the approximate latitudes of the southern and northern boundary of each SGS zone. SGS zone boundaries often follow state/provincial boundaries instead of latitude lines, so we approximated the boundaries of each zone using $36.5^{\circ}$ north latitude as the southern boundary of zone $1,39^{\circ}$ north as the boundary between zones 1 and $2,42^{\circ}$ north as the boundary between zones 2 and $3,44^{\circ}$ north as the boundary between zones 3 and $4,46^{\circ}$ north as the boundary between zones 4 and 5 , and $52^{\circ}$ north as the northern boundary of zone 5 . To visualize the arrival dates at breeding-period sites in reference to the start of the survey window in each zone, we plotted locations on arrival dates along with SGS zone boundaries (Fig. 3). We divided

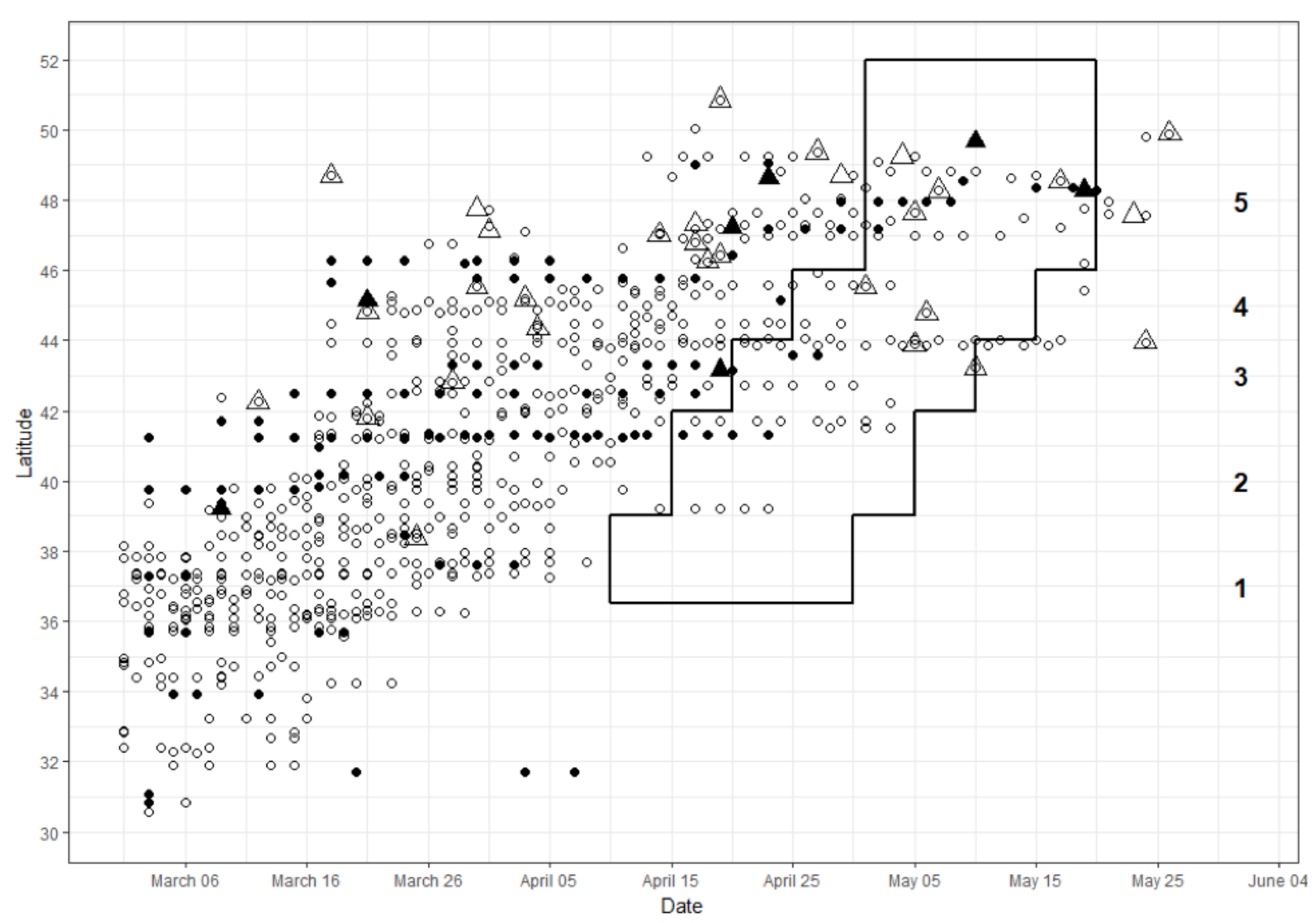

Figure 2: Date and latitude in which a PTT-marked American woodcock was present at a migratory stopover site (points), and date and latitude in which a PTT-marked woodcock arrived at a breeding-period site (triangles) for 40 PTT-marked woodcock during spring 2014, 2015, and 2016. Males are represented with solid points and triangles and females are represented with hollow points and triangles. The stair step polygon represents the opening and closing dates of each SGS survey window and the approximate latitude of the southern and northern boundary of each SGS zone. Points located to the left of the polygon represent migratory woodcock present at stopover sites before the start of the survey window. Points within the polygon represent transient woodcock that may have been present during a survey window before reaching their final breeding-season sites. Points to the right of the polygon represent woodcock at migratory stopover sites after the close of the SGS survey window in that zone. Triangles to the left of the polygon represent woodcock that arrived at breeding-period sites before the start of the SGS survey window, triangles within the polygon represent woodcock that arrived at breeding-period sites during the survey window, and triangles to the right of the polygon represent woodcock that arrived at breeding-period sites after the survey window. 
and symbolized the breeding-period sites based on 3 categories: 1) woodcock that arrived at breeding-period sites before the start of the survey window, 2) woodcock that arrived at breeding-period sites during the survey window, and 3) woodcock that arrived at breeding-period sites after the close of the survey window.

\section{Results}

We tracked 40 transmitter-marked woodcock throughout spring migration and determined their migratory stopover and breeding-period sites. We determined the date of arrival at breeding-period sites for 37 woodcock. Of the 37 woodcock for which we determined breeding-period site arrival dates, 30 were captured during the wintering period (Texas: $n=8$, Louisiana: $n=22$ ) and 7 were captured during the breeding period of the previous year (Michigan: $n=3$, Minnesota: $n=4$ ). Woodcock captured during the previous breeding period still had functional transmitters during spring migration, enabling us to determine breeding-period locations and arrival dates.

Mean arrival date at breeding-period sites was 18 April (range $=8$ March -25 May), and mean arrival date was similar for males (17 April, SE $=9.6$ days) and females (18 April, SE $=3.9$ days). There was no difference in the arrival date at breeding-period sites by $\operatorname{sex}\left(\mathrm{F}_{1,35}=0.034, P\right.$ $=0.86$, males: $n=7$, females: $n=30$ ).

Of the 40 marked woodcock monitored during spring migration with known breeding-period sites, 33 were captured during the wintering period (Texas: $n=9$, Louisiana: $n=24$, male $n=9$, female $n=14)$. Ten breeding-period sites (30\%, male: $n=5$, female: $n=5$ ) were outside of potential SGS coverage (Fig 1), with woodcock breeding-period sites outside of coverage in Missouri $(n=1)$, Ontario $(n=5)$, Quebec $(n=3)$, and South Dakota $(n=1)$.

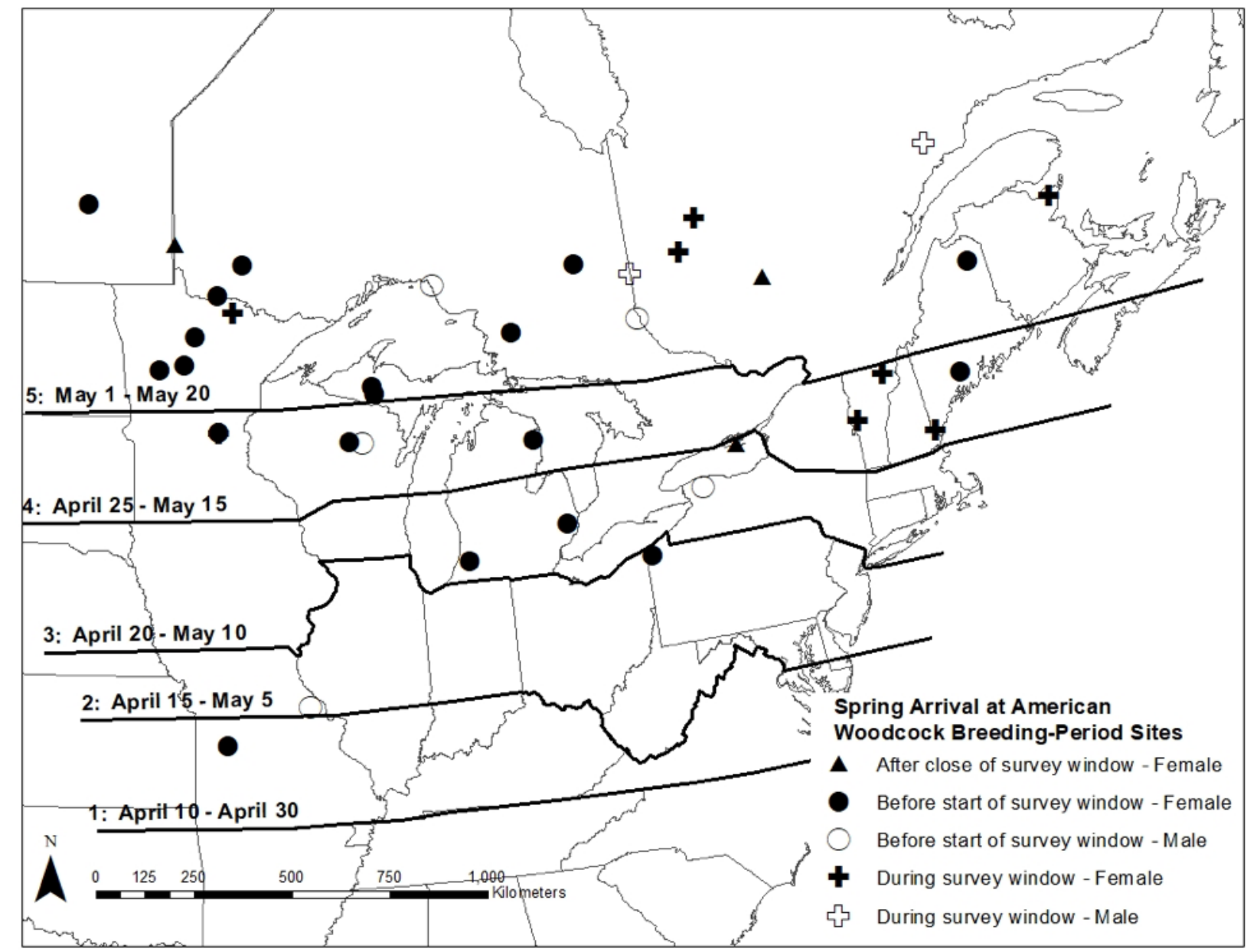

Figure 3: Timing of arrival of 37 PTT-marked American woodcock at breeding-period sites in relation to singingground survey (SGS) windows in each survey zone. Twenty-four woodcock (65\%) arrived at breeding-period sites prior to the survey window. Three woodcock (8\%) arrived after the survey window. Ten woodcock arrived during the survey window $(27 \%)$. 
Fourteen of the 33 monitored woodcock captured during the wintering period migrated to breeding sites in Canada, whereas the remainder $(n=19)$ migrated to breeding sites in the U.S. We documented 1 woodcock breeding-period site in zone 1,2 in zone 2,4 in zone 3,7 in zone 4 , and 19 in zone 5.

Transient woodcock were present in zones $2-5$ during the survey window (Fig. 2). Transient male woodcock displaying during the survey window have the potential to be counted as breeding woodcock by the SGS. Thirteen (male: $n=2$, female: $n=11$ ) of the 37 monitored woodcock with known breeding-period site arrival dates (35\%) were migrating through a survey zone during an active survey window. These woodcock fell into $\geq 1$ of the following categories: woodcock that were present at stopover during an open survey window in a Management Region other than the Management Region of their breeding-period site ( $n=$ 2 ), woodcock that were present at stopover during an open survey window in a survey zone other than the survey zone of their breeding-period site $(n=7)$, woodcock that were present at a stopover site during an open survey window in a state/province other than the state or province of their breeding-period site $(n=7)$, and woodcock that were present at a stopover site during an open survey window in the same state or province as their breeding-period site ( $n=7$, see Fig. 4 for examples of each of these categories).

Most woodcock $(n=24,65 \%)$ arrived in their respective breeding-period sites before the survey window opened (Fig. 3); therefore they were present during the entire survey period. Ten woodcock $(27 \%)$ arrived at breeding-period sites after the start of the survey window but before the window closed (Fig. 3 ). Only 3 woodcock (8\%) arrived at breeding-period sites after the close of the survey window. Of the 7 transmitter-marked males for which we determined breeding-season sites, 5 arrived at those sites before the start of the survey window and 2 arrived during the survey window. All 13 woodcock that arrived at breeding-period sites after the start of survey windows settled on breeding-period sites in zones $3-5$, with most in zone $5(n=8)$, followed by zone $4(n=4)$, and zone $3(n=1)$.

\section{Discussion}

Our ability to monitor satellite-marked woodcock over the course of spring migration allowed us to determine where individuals were with respect to the survey windows for each zone of the SGS. Previous attempts to set zone windows were based on observations of unmarked woodcock (Goudy 1960, Duke 1966, Tautin et al. 1983) for which migratory status was unknown. Our results provide the first assessment of the match between when woodcock return to breeding-season sites and the survey windows for the SGS, and can be used to assess whether current zone windows are effective at minimizing bias from inclusion of transient woodcock.
Stopover locations of migrating woodcock with respect to each SGS zone window indicated that in all zones, except in zone 1, some migrating woodcock were present during a survey window before reaching their final breeding-season sites. This pattern was more evident in the more northern zones 3, 4, and 5. Woodcock are known to display courtship behavior during spring migration (Jacobs 2001), and may therefore be considered resident woodcock if they are present and detected in a zone other than the zone of their breeding-season site under the SGS protocol. However, limitations to our study include: (1) our sample consisted of both male and female woodcock whereas the SGS counts only males, (2) the difference in the extent of display between transient and resident woodcock is unknown, and (3) a woodcock present in an active survey zone may not be present at a SGS survey stop and would therefore not affect survey results.

Counting migrating woodcock as residents has consequence. During our study, 7 transmitter-marked woodcock $(17.5 \%)$ were present at a migratory stopover in a zone when the survey window was open and later moved to a breeding-period site in a zone farther north. Male woodcock following these patterns could be misclassified as resident woodcock or counted in $>1$ zone, state/province, or Management Region. The ramification of these possible movements is that counts recorded during the SGS (typically expressed as the mean number of males per survey stop) may be biased upward or downward, with the magnitude of bias determined by the prevalence of such double counting within zones. These biases may in turn influence short-term trends or perceived spatial variation in relative woodcock abundance. Movement among smaller-sized states/provinces would be more likely than among larger-sized states/provinces or Management Regions simply because of the distances involved. For example, a woodcock could easily move from Vermont to New Hampshire in a short period relative to moving from, for example, western Ontario to eastern Quebec during that same period. Under those circumstances, the indices/trends in these smaller political units (e.g. states/provinces) could be more affected by such movements than in larger political units. No monitored woodcock chose breeding-period sites in zones 1 or 2 . This may be due to bias from capturing woodcock in only a portion of their range. Therefore, our analysis of SGS timing and extent is most relevant to the three northernmost zones. To better understand rangewide patterns, woodcock would need to be captured in additional states or provinces and similarly monitored.

Arrival of resident birds before the start of the survey window may result in lower detection probability during the survey window. Duke (1966) addressed seasonal variation in woodcock singing during the breeding season. Early in the breeding season, both resident and migrating woodcock were present based on the observa- 
tion that territorial interactions were frequent. Territorial behavior is when one male chases another male in the singing ground while uttering the characteristic "cackling call" (Mendall and Aldous 1943). According to Duke (1966:699), "Overt territorial behavior did not last beyond the first week of April...and does not affect the survey." Once migrants moved through the study area, Duke (1966) concluded that courtship activity decreased and was constant through mid-May during a "stable" period when no migrants were present. This period was analogous to
Goudy's (1960) "central period," which was defined as the period when courtship activity was consistent based on a series of similar SGS counts. Goudy (1960) concluded that the timing of this central period varied annually based on differences in weather conditions-earlier in warm springs and later in cold springs. Dwyer et al. (1988) documented that VHF radio-marked woodcock in Maine moved among singing grounds over the course of the breeding season and that these movements could entail territorial disputes. Bergh (2011) estimated detection probabili-

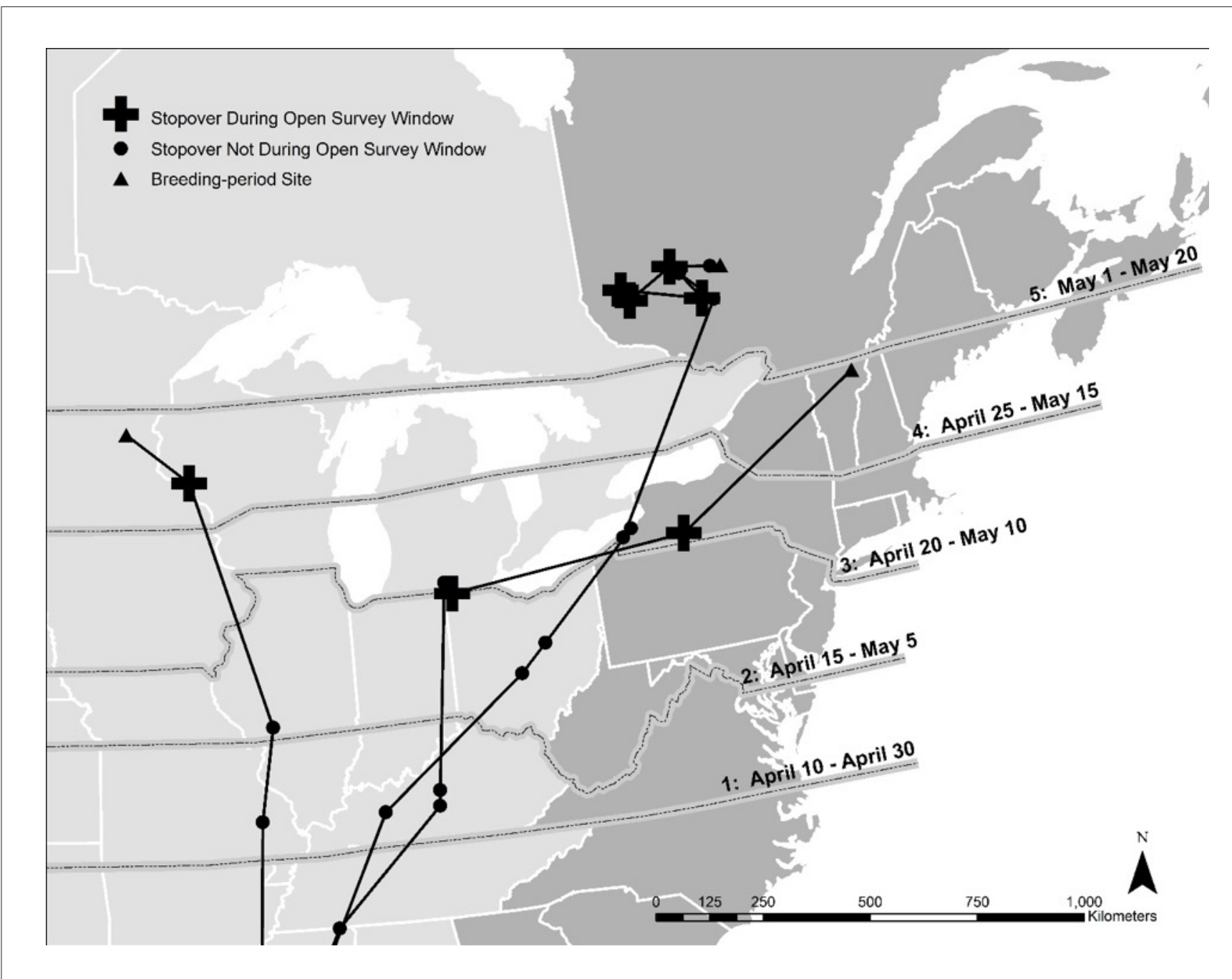

Figure 4. Spring migration paths of 3 transmitter-marked American woodcock that were present at a migratory stopover during a survey window of the SGS. The paths are representative of woodcock that were present at stopover during an open survey window in a Management Region other than the Management Region of their breedingperiod site (breeding-period site furthest east), woodcock that were present at stopover during an open survey window in a survey zone other than the survey zone of their breeding-period site (breeding-period site furthest east), woodcock that were present at a stopover site during an open survey window in a state/province other than the state or province of their breeding-period site (breeding-period site furthest west and breeding-period site furthest east), and woodcock that were present at a stopover site during an open survey window in the same state or province as their breeding-period site (breeding-period site center).The Central Management Region is shown in light gray and the Eastern Management Region is shown in dark gray. 
ties of unmarked woodcock along 8 routes (4 SGS routes and 4 randomly located routes) in Minnesota. Bergh (2011) divided her sampling period into 3, 2-week periods (early, mid-, and late spring), and found substantial support for a model that allowed detection to vary by period. The peak of detection was in the last week of April and first week of May, and was lower both before and after this middle period. She suggested that the peak in woodcock detections was coincident with Goudy's (1960) stable period, and that narrowing the SGS zone window dates to coincide with the peak display period may present logistical challenges. However, Bergh (2011) worked with unmarked woodcock, so was not able to determine whether individual woodcock singing rates change over the season. Further studies with marked woodcock would likely be necessary to determine whether the stable period of Goudy (1960) and Duke (1966) varies both within and among years.

Woodcock arriving at breeding-period sites before the start of the survey have the potential to be surveyed at the correct site throughout the entire survey window. This is the circumstance for which the SGS was designed (Duke 1966, Cooper and Kelley 2010). Alternatively, woodcock arriving during the survey window cannot be surveyed at their breeding-period sites during the period before they arrived; woodcock arriving after the close of the survey window cannot be surveyed at their breeding-period sites. These 2 situations result in undercounting in the areas where woodcock arrive after the beginning of the survey window. In our sample of transmitter-marked woodcock, late-arriving individuals were concentrated in the 2 northernmost zones, whereas transient woodcock present during a survey window were concentrated in zones 2-5 (Fig. 3). The combination of these situations may result in the SGS weighing too heavily the contribution of routes in southern portion of the primary breeding range while weighing too lightly the routes in the northern portion of the primary breeding range. One solution to these problems would be to open survey windows later, provided that the survey window does not extend later than the "stable" period described by Goudy (1960) to avoid undercounting. Delaying each zone opener by 2 weeks would reduce, but not eliminate, the effect of woodcock migrating through a zone during a survey window (Fig. 2). Whether such a delay should be focused more on certain zones is unclear, but based on our observations, zone 5 might most benefit delaying beginning of the survey window. We note that altering survey windows is not trivial and many issues need to be considered. For example, in Canada, altering survey windows would require consideration of weather conditions, road conditions, and the availability of staff and volunteers (K. Jones, Bird Studies Canada, pers. communication). Additionally, changes to survey windows would have ramifications for interpreting long-term trends.
Although we found no difference in arrival dates based on sex, our sample consisted of only 7 males. Future research focused on tagged males may provide additional insight into survey windows that minimize mismatch between timing of surveys and presence of male woodcock at breeding-season sites. Future modeling simulating migration may help elucidate how transience affects trend estimation and how changes to survey zone timing may alter interpretation of SGS trends.

Our results indicate that SGS coverage encompassed the majority of woodcock breeding-period sites within the U.S. $(n=17,92 \%)$ and approximately half of the breeding period sites in Canada $(n=6,43 \%)$. Canadian locations outside of SGS coverage were mostly north of the area currently covered by the survey (Fig. 1). Incomplete coverage in Canada may obscure population trends, especially if woodcock range shifts north due to climate change or changes in land use. As Sauer et al. (2006) suggested, survey cooperators need to better-define the northern extent of the SGS, especially if evidence indicates a northward expansion of the woodcock breeding range. However, increasing the area covered by the SGS in Canada is not trivial for the same reasons as altering zone dates, and because of the associated logistical considerations for surveying road-based routes in remote areas.

Finally, it is not clear whether the relative contribution of woodcock recruitment among zones is changing with changing climatic conditions (Galbraith et al. 2014). Thogmartin et al. (2007) predicted woodcock abundance based on the SGS in the U. S. and estimated that the lowest abundances occurred in zone 1 and the highest abundances occurred in zone 5, which suggests that improving the timing of zone 5 window dates and expanding the survey extent in Canada could result in more accurate abundance estimates upon which to make management decisions.

\section{Management Recommendations}

We suggest that additional information is necessary to evaluate whether current SGS zone windows are sufficient, or whether they need to be changed. We recommend that future studies continue to use PTT and GPS technology to monitor migration of individual woodcock captured across the species' range. Advancements in transmitter technology will likely result in lighter transmitters produced for reduced expense, allowing for increased sample sizes, especially of male woodcock. An expanded effort to monitor woodcock migration will allow a more in-depth and robust examination of SGS windows and survey extent. The results of our study suggest that survey windows could be delayed by 2 weeks to avoid counting migrating woodcock and that the survey extent could be expanded northward in Canada to provide more coverage of that portion of the woodcock breeding range with the highest breeding density. 


\section{Acknowledgments}

We thank all of the people who have banded woodcock and reported band recoveries, the U.S. Geological Survey Bird Banding Laboratory, and everyone who assisted in capturing and marking woodcock for this study. Any use of trade, firm, or product names is for descriptive purposes only and does not imply endorsement by the U.S. Government. The findings and conclusions in this article are those of the authors and do not necessarily represent the views of the U.S. Fish and Wildlife Service. This research was funded by the American Woodcock Society and Ruffed Grouse Society, the Glassen Foundation, Louisiana Department of Wildlife \& Fisheries, Michigan Department of Natural Resources, U.S. Fish and Wildlife Service Webless Migratory Game Bird Program, University of Arkansas, the U.S. Geological Survey Arkansas Cooperative Fish and Wildlife Research Unit, the U.S. Geological Survey Minnesota Cooperative Fish and Wildlife Research Unit, Texas Parks \& Wildlife Department, and Woodcock Limited.

\section{Literature Cited}

Argos. 2016. Argos User's Manual. <http://www.argos-system.org/ manual/>. Accessed 13 May 2016.

Arizaga, J., A. Crespo, I. Telletxea, R. Ibáñez, F. Díez, J.F. Tobar, M. Minondo, Z. Ibarrola, J.J. Fuente, and J.A. Pérez. 2014. Solar/ Argos PTTs contradict ring-recovery analyses: woodcocks wintering in Spain are found to breed further east than previously stated. Journal of Ornithology 156:515-523.

Bergh, S.M. 2011. Factors influencing detection of American woodcock during singing-ground surveys. Thesis, University of Minnesota, Minneapolis, Minnesota, USA.

Blankenship, L.H. 1954. Investigations on woodcock in Michigan. Special Scientific Report - Wildlife No. 2:41-48. U.S. Fish and Wildlife Service, Washington, D.C., USA.

Cooper, T.R., and J.R. Kelley, Jr. 2010. Status of American woodcock and woodcock surveys in North America. Pages 135-145 in C.A. Stewart, and V.R. Frawley, editors. Proceedings of the Tenth American woodcock symposium, Roscommon, Michigan, USA.

Douglas, D.C., R. Weinzierl, S.C. Davidson, R. Kays, M. Wikelski, and G. Bohrer. 2012. Moderating Argos location errors in animal tracking data. Methods in Ecology and Evolution 3:999-1007.

Duke, G.E. 1966. Reliability of censuses of singing male woodcocks. Journal of Wildlife Management 30:697-707.

Dwyer, T.J., G.F. Sepik, E.L. Derleth, and D.G. McAuley. 1988. Demographic characteristics of a Maine woodcock population and effects of habitat management. U.S. Fish and Wildlife Service. Fish and Wildlife Report 4. 29pp.

Galbraith, H., D.W. DesRochers, S. Brown, and J.M. Reed. 2014. Predicting vulnerabilities of North American shorebirds to climate change. PLOS One https://doi.org/10.1371/journal.pone.0108899.

Goudy, W.H. 1960. Factors affecting woodcock spring population indexes in southern Michigan. Thesis, Michigan State University, East Lansing, Michigan, USA.

Hughes, R.J., A. Reed, and G. Gauthier. 1994. Space and habitat use by greater snow goose broods on Bylot Island, Northwest Territories. Journal of Wildlife Management 58:536-545.

Jacobs, B. 2001. Birds in Missouri. Missouri Department of Conservation, Jefferson City, Missouri, USA.

Kelley, J.R., Jr., S. Williamson, and T R. Cooper, editors. 2008. American woodcock conservation plan: a summary of and recommendations for conservation in North America. Wildlife Management Institute, Washington, D.C., USA.

Kozicky, E.L., T.A. Bancroft, and P.G. Homeyer. 1954. An analysis of woodcock singing ground counts, 1948-1952. Journal of Wildlife Management 18:259-266.

Kranstauber, B., A. Cameron, R. Weinzerl, T. Fountain, S. Tilak, M. Wikelski, and R. Kays. 2011. The Movebank data model for animal tracking. Environmental Modelling \& Software 26:834-835.

Loman, Z.G., E.J. Blomberg, W.V. Deluca, D.J. Harrison, C.S. Loftin, and P.B. Wood. 2017. Landscape capability predicts upland game bird abundance and occurrence. Journal of Wildlife Management 81:1110-1116.

Martell, M.S., C.J. Henny, P.E. Nye, and M.J. Solensky. 2001. Fall migration routes, timing, and wintering sites of North American ospreys as determined by satellite telemetry. Condor 103:715.

Martin, F.W. 1964. Woodcock age and sex determination from wings. Journal of Wildlife Management 28:7.

McAuley, D.G., J.R. Longcore, and G.F. Sepik. 1993. Techniques for research into woodcocks: experiences and recommendations. Biological Report, Federal Government Series, U.S. Fish and Wildlife Service, Washington, D.C., USA.

Mendall, H.L. 1955. Woodcock census studies in northeastern United States - 1954. Special Scientific Report - Wildlife No. 28:13-18. U.S. Fish and Wildlife Service, Washington, D.C., USA.

Mendall, H.L., and C.M. Aldous. 1943. The ecology and management of American woodcock. Maine Cooperative Wildlife Research Unit. University of Maine, Orono, Maine, USA.

Moore, J.D., 2016. Migration ecology of American woodcock (Scolopax minor). Thesis, University of Arkansas, Fayetteville, Arkansas, USA.

Morrison, M., K.J. Connor, and G.J. Forbes. 2010. GIS-based assessment of American woodcock habitat at two spatial scales in New Brunswick. Pages 53-61 in C.A. Stewart, and V.R. Frawley, editors. Proceedings of the Tenth American woodcock symposium, Roscommon, Michigan, USA.

Nelson, M.R., and D.E. Andersen. 2013. Do singing-ground surveys reflect American woodcock abundance in the western Great Lakes region? Wildlife Society Bulletin 37:585-595.

Olson, B.E., K.A. Sullivan, and A.H. Farmer. 2014. Marbled godwit migration characterized with satellite telemetry. Condor 116:185-194.

Rappole, J.H., and A.R. Tipton. 1991. New harness design for attachment of radio transmitters to small passerines. Journal of Field Ornithology 62:335-337.

Rieffenberger, J.C., and R.C. Kletzly. 1967. Woodcock night-lighting techniques and equipment. U.S. Bureau of Sport Fisheries and Wildlife, Special Science Report-Wildlife, Number 101.

Sauer, J.R., W.A. Link, W.L. Kendall, J.R. Kelley, and D.K. Niven. 2006. A hierarchical model for estimating change in American woodcock populations. Journal of Wildlife Management 72:204-214.

Seamans, M.E., and R.D. Rau. 2019. American woodcock population status. Pages 9-16 in D.G. Krementz, D.E. Andersen, and T. R. Cooper, Editors. Proceedings of the Eleventh American Woodcock Symposium. University of Minnesota Libraries Publishing, Minneapolis, Minnesota, USA.

Streby, H.M., T.L. McAllister, S.M. Peterson, G.R. Kramer, J.A. Lehman, and D.E. Andersen. 2015. Minimizing marker mass and handling time when attaching radio-transmitters and geolocators to small songbirds. Condor 117:249-255.

Tautin, J. 1982. Assessment of some important factors affecting the singing-ground survey. Pages 6-11 in T.J. Dwyer and G.L. Storm, technical coordinators. Woodcock ecology and management. U.S. Fish Wildlife Service, Wildlife Research Report 14, Washington, D.C., USA.

Tautin, J., P.H. Geissler, R.E. Munro, and R.S. Pospahala. 1983. Monitoring the population status of American woodcock. Trans- 
[5] SINGING-GROUND SURVEY EVALUATION • Proceedings of the Eleventh American Woodcock Symposium

actions of the North American Wildlife and Natural Resources Conference 48:376-388.

Thogmartin, W E., J.R. Sauer, and M.G. Knutson. 2007. Modeling and mapping abundance of American woodcock across the midwestern and northeastern United States. Journal of Wildlife Management 71:376-382.

Whitcomb, D.A. 1974. Characteristics of an insular woodcock population. Michigan Department of Natural Resources, Wildlife Division Report 2720. Lansing, Michigan, USA.

Whiting, R.M., Jr. 2010. American woodcock singing-ground surveys: should they be expanded? Pages 153-159 in C.A. Stewart, and V.R. Frawley, editors. Proceedings of the Tenth American woodcock symposium, Roscommon, Michigan, USA.

Wikelski, M., and R. Kays. 2016. Movebank: archive, analysis and sharing of animal movement data. <https://www.movebank. org $>$. Accessed 13 May 2016

Woodcock Harvest Strategy Working Group. 2010. Interim American woodcock harvest strategy. A Proposal to the Atlantic Flyway Council, Mississippi Flyway Council, Central Flyway Council, and the U.S. Fish and Wildlife Service. 11pp. 